\title{
Editorial
}

\section{Critical and Alternative Perspectives on Student Engagement}

Higher Education Policy (2017) 30, 1-4. doi:10.1057/s41307-016-0026-4

At a policy level, 'student engagement' is attracting increasing attention internationally as a core element of institutional learning and teaching strategies and through national student engagement surveys in most developed higher education systems. In parallel, a growing literature has sought to define 'student engagement' and develop pedagogic strategies to increase student engagement. An alternative literature, however, is beginning to emerge which is questioning the meaning of student engagement, whether strategies are effective in producing learning gain, and critiquing their behavioural effects on students. This special issue brings together papers which offer critical and alternative perspectives on student engagement from these, or other perspectives.

'Student engagement' is a nebulous and contentious term subject to multiple interpretations (Trowler, 2010). It implies a series of conceptual commitments, teaching strategies and behavioural orientations expected of students. Driven in part by efforts to improve student completion and success rates at university, and underpinned by a pedagogic philosophy based on social constructivism, the student engagement movement has its roots in the US, symbolised by the National Student Engagement Survey (from 2000). Subsequently, this survey instrument has spread to most other developed higher education systems (Coates and McCormick, 2014) and spawned multiple institutional level initiatives designed to identify and support those students deemed to be 'at risk of disengaging from their learning and their institution' (Nelson et al., 2012, p. 83). Yet, student engagement remains weakly theorised (Kahn, 2014) and may also be interpreted as a form of distributed agency from a critical realist perspective.

While student engagement is increasingly recognised internationally and nationally as key to learning gain and student achievement in higher education (Pascarella et al., 2010), close examination of the evidence suggests mixed results. Questions remain over what constitutes research-informed high-impact pedagogies (Kuh, 2008) within specific disciplines and in relation to specific dimensions of student engagement. The role that students play as co-constructors of university quality enhancement also needs exploration, and how such roles are potentially conditioned by the institutional context.

Student engagement implies a learning environment where participants, drawn from diverse backgrounds, are actively engaged in a participatory culture and 
experience an adequately resourced and interactive approach to teaching (Newswander and Borrego, 2009). However, the behavioural effects of policies which promote student engagement, particularly compulsory attendance and class participation, are beginning to be questioned by a number of researchers (e.g. Zepke, 2014; Gourlay, 2015; Macfarlane, 2015) raising concerns about the effects of neo-liberalism, and the implications for the freedom of students to learn in the face of a growing surveillance culture at university.

This special issue brings together contributions that represent critical or alternative perspectives on student engagement. They are alternative in the sense that they do not approach student engagement, as the overwhelming bulk of the literature does, as a positive and unproblematic goal on the basis of an oft-cited link between levels of student engagement at university and academic achievement. Alternative and critical perspectives tend to take issue with the orthodox literature in two ways: questioning the extent to which engagement strategies lead to higher levels of academic achievement (i.e. the 'effectiveness' argument); and secondly, the manner in which student engagement policies and associated pedagogic practices can impact negatively on students in terms of fairness and freedom.

In the first paper in this special issue, Bruce Macfarlane and Michael Tomlinson provide an analysis of the various critiques of student engagement within the literature. Drawing on neo-liberalism as a contemporary ideology, six critiques of student engagement are explored: performativity, marketing, infantilisation, surveillance, gamification and opposition. Lesley Gourlay questions the way that commonly asserted instantiations of student engagement, especially learning that is considered 'active' or 'collaborative', is valorised, whilst other dispositions such as silence and passivity are regarded as problematic. Her analysis warns against what she calls 'learnification' and the disparagement of practices that are labelled 'teacher-centred'. Michael Tomlinson approaches the analysis of student engagement through a policy sociology lens, identifying its macro, meso and micro dimensions. His paper illustrates how this approach enables us to explore why this policy agenda has become so pervasive, its related socio-political and institutional drivers, as well as its contested meanings at the level of practice.

Peter Kahn uses a critical realist lens as a basis to interrogate existing policy frameworks arguing that the agency of students is key to social relations. His paper raises salient policy issues in relation to the enhancement of cultural and social relationships between students and their institutions. Manja Klemenčič contends that student engagement policies are overly influenced by behaviourist conceptions and that student-centredness represents a meta-concept that ought to inform the development of policy. A student-centred approach, she argues, is much more in tune with the recognition of the student's agency and capabilities to intervene in and influence their learning environment.

Drawing on Foucault's metaphor of the panopticon and Siemen's (2005) connectivist theory, Julie Wintrup questions the ethical implications of learning 
analytics as a means of monitoring student engagement in learning. Finally, Paul Kelly, Nic Fair and Carol Evans argue that the British government's most recent proposals to evidence teaching 'excellence' in UK universities represent a transactional model of student engagement, linked to measurable indicators of student effort. In their view, there is a need for a more nuanced and democratic conception of student engagement through pedagogic strategies that emphasise cocreation, co-design and co-regulation.

Many of the papers are focused on exploring, as Peter Kahn puts it in his contribution to this special issue, the assumptions that underpin existing policy frameworks. The neo-liberal basis of these assumptions in relation to student engagement is emphasised by a number of contributors (e.g. Macfarlane and Tomlinson; Tomlinson; Kelly, Fair and Evans) along with its moral or ethical impacts on students as learners, especially in papers by Gourlay and Wintrup, respectively. There are also alternative visions of what student engagement policies ought to look like by reference to student-centred as a principle and the centrality of student agency and democratic pedagogic practices put forward by Klemenčič, Kahn, and Kelly, Fair and Evans.

Collectively, these papers represent an attempt to question the types of measurable data that are being used to evidence student engagement and coming to define the policies of universities in systems across the world. None of us would argue that student engagement is not a laudable aim but that there is a need to revisit how strategies might be broadened to promote genuinely student-centred, democratic goals that respect the rights of students as learners.

Bruce Macfarlane and Michael Tomlinson Southampton Education School, Highfield Campus, Southampton SO17 1BJ, Hampshire, England, UK

E-mail: bmachku@gmail.com

\section{References}

Coates, H. and McCormick, A.C. (eds.) (2014) Engaging University Students: International Insights from System-Wide Studies, Dordrecht: Springer.

Gourlay, L. (2015) 'Student engagement and the tyranny of participation', Teaching in Higher Education 20(4): 402-411.

Kahn, P. (2014) 'Theorising student engagement in higher education', British Educational Research Journal 40(6): 1005-1018.

Kuh, G.D. (2008) High-Impact Educational Practices: What They Are, Who Has Access to Them, and Why They Matter, Washington DC: American Association for Colleges and Universities.

Macfarlane, B. (2015) 'Student performativity in higher education: converting learning as a private space into a public performance', Higher Education Research and Development 34(2): 338-350.

Nelson, K.J., Quinn, C., Marrington, A. and Clarke, J.A. (2012) 'Good practice for enhancing the engagement and success of commencing students', Higher Education 63(1): 83-96. 
Newswander, L.K. and Borrego, M. (2009) 'Engagement in two interdisciplinary graduate programs', Higher Education 58(4): 551-562.

Pascarella, E.T., Seifert, T.A. and Blaich, C. (2010) 'How effective are the NSSE benchmarks in predicting important educational outcomes?' Change: The Magazine of Higher Learning 42(1): $16-22$.

Trowler, V. (2010) Student engagement literature review, York: The Higher Education Academy.

Zepke, N. (2014) 'What future for student engagement in neo-liberal times?', Higher Education 69(4): 693-704. 